\title{
Phytoplankton photosynthetic capacity in a shallow estuary: environmental correlates and interannual variation
}

\author{
Charles L. Gallegos* \\ Smithsonian Environmental Research Center, PO Box 28, Edgewater, Maryland 21037, USA
}

\begin{abstract}
Parameters in the photosynthesis-irradiance (P-E) relationship of phytoplankton were measured at weekly to bi-weekly intervals for $20 \mathrm{yr}$ at 6 stations on the Rhode River, Maryland (USA). Variability in the light-saturated photosynthetic rate, $P^{B}{ }_{\max }$, was partitioned into interannual, seasonal, and spatial components. The seasonal component of the variance was greatest, followed by interannual and then spatial. Physiological models of $P^{B}{ }_{\max }$ based on balanced growth or photoacclimation predicted the overall mean and most of the range, but not individual observations, and failed to capture important features of the seasonal and interannual variability. $P^{B}{ }_{\max }$ correlated most strongly with temperature and the concentration of dissolved inorganic carbon

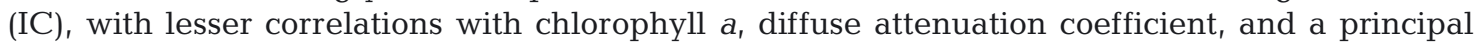
component of the species composition. In statistical models, temperature and IC correlated best with the seasonal pattern, but temperature peaked in late July, out of phase with $P^{B}{ }_{\max }$, which peaked in September, coincident with the maximum in monthly averaged IC concentration. In contrast with the seasonal pattern, temperature did not contribute to interannual variation, which instead was governed by IC and the additional lesser correlates. Spatial variation was relatively weak and uncorrelated with ancillary measurements. The results demonstrate that both the overall distribution of $P^{B}{ }_{\max }$ and its relationship with environmental correlates may vary from year to year. Coefficients in empirical statistical models became stable after including 7 to $10 \mathrm{yr}$ of data. The main correlates of $P^{B}{ }_{\text {max }}$ are amenable to automated monitoring, so that future estimates of primary production might be made without labor-intensive incubations.
\end{abstract}

KEY WORDS: Phytoplankton - Photosynthesis - Primary production - Estuary - Rhode River · Interannual variability

\section{INTRODUCTION}

The photosynthetic conversion of $\mathrm{CO}_{2}$ into reduced particulate carbon by phytoplankton provides the major input of fixed carbon into the pelagic food web, and is a major flux in the global carbon cycle. Photosynthesis is a light-dependent process, and consequentially the light-response curve of photosynthesis (the photosynthesis-irradiance, P-E, curve) has been the subject of much study aimed at developing a predictive understanding of primary production and its environmental controls (Ryther \& Yentsch 1957, Harding et al. 2002).
The typical features of the P-E curve have been reviewed extensively and modeled both empirically (Jassby \& Platt 1976, Platt et al. 1980) and mechanistically (Fasham \& Platt 1983, Behrenfeld et al. 2002, 2004). The primary features of interest are the initial slope of the P-E curve at low light intensities, $\alpha_{b}$, which is the primary determinant of the depthintegrated production in optically deep waters (Lewis et al. 1985), and the maximal rate at light saturation, $P^{B}{ }_{\text {max }}$, the main determinant of primary production near the surface (Behrenfeld et al. 2002) and in optically shallow water (Lorenzo et al. 2004). The superscripted $B$ in the notation indicates the customary 
practice of normalizing the rate of photosynthesis to the concentration of chlorophyll a $(\mathrm{chl} a)$, which is easily measured and amenable to satellite remote sensing (Platt \& Sathyendranath 1988).

Parameters of the P-E curve are typically measured over seasonal cycles in studies from 1 to several years duration (Domingues et al. 2011, Gameiro et al. 2011). $P^{B}{ }_{\max }$ typically displays a seasonal pattern with a winter minimum and summer maximum, driven principally by temperature (Lohrenz et al. 1994, Gameiro et al. 2011). Day-to-day variation in $P^{B}{ }_{\text {max }}$ has also been shown to be substantial (Côté \& Platt 1983), as has diurnal cycling (Harding et al. 1982). Interannual variation in P-E parameters has not been widely studied, although Harrison \& Platt (1980) mentioned that separate years were statistically indistinguishable in their analysis of $8 \mathrm{yr}$ of data from Bedford Basin, Nova Scotia (Canada).

Several models for estimating $P^{B}{ }_{\text {max }}$ from environmental factors have been derived, incorporating varying degrees of physiological detail (Cullen 1990, Cloern et al. 1995, Behrenfeld et al. 2002, see review by MacIntyre et al. 2002). One widely adopted approach links photosynthesis to phytoplankton growth rate via the cellular chl $a$ to carbon ratio, chl:C, which depends on light, temperature, and nutrients (Cloern et al. 1995). Using an approach based on photoacclimation, Behrenfeld et al. (2002) parameterized separate light-dependent relationships for relative changes in Calvin cycle capacity and cellular chlorophyll for nutrient-deficient and -sufficient conditions. Models represent hypotheses about the relative strength of controlling factors, and their use with measurements can help reveal the relative importance of different factors in the situation of interest. Moreover, possession of a suitably verified model is the best prospect for obtaining reliable future estimates of P-E parameters in the absence of continuing measurements.

Concerns about climate and atmospheric change indicate that there is a need for long-term measurements of factors governing phytoplankton primary production. Two of the factors of concern, temperature and $\mathrm{CO}_{2}$ concentration, are of direct importance in the photosynthesis process. The objectives of this work were therefore to determine the patterns and controls on the P-E parameters of phytoplankton in a shallow eutrophic estuary, with emphasis on variations in the maximal photosynthesis rate normalized to chl $a, P_{\text {max }}^{B}$. Presented here are measurements and analysis of $P^{B}{ }_{\max }$ and environmental correlates from the Rhode River, Maryland (USA), a shallow tributary of Chesapeake Bay, collected at weekly to bi- weekly intervals for $20 \mathrm{yr}$. The ability of 2 simple physiologically based models to reproduce temporal and spatial patterns in the measurements are examined, and statistical models based on ancillary measurements are derived. In this system, interannual variability is substantial, and appears to be driven more by changes in inorganic carbon concentrations than by temperature.

\section{MATERIALS AND METHODS}

\section{Study site}

The Rhode River $\left(38^{\circ} 52^{\prime} \mathrm{N}, 76^{\circ} 31^{\prime} \mathrm{W}\right)$ is a shallow, eutrophic tributary on the western shore in the mesohaline zone of Chesapeake Bay in Maryland (USA). The average tidal range is about $30 \mathrm{~cm}$, although larger changes in depth are driven by atmospheric pressure gradients or strong winds that move water into or out of the main axis of Chesapeake Bay (Jordan et al. 1991a). Salinity varies from 0 at the head following runoff events to nearly 20 at the mouth following prolonged droughts. The system has been the subject of long-term studies of nutrients and chlorophyll (Jordan et al. 1991a,b), phytoplankton blooms and species composition (Gallegos et al. 1997, 2010), and fish and invertebrates (Hines et al. 1990). Average depth of the Rhode River is $2 \mathrm{~m}$ and varies from $4 \mathrm{~m}$ at the mouth to $<1 \mathrm{~m}$ in an area of broad subtidal mudflats near the head. The estuary is usually well mixed vertically (Seliger \& Loftus 1974), although subsurface peaks in the concentration of chl a are sometimes present near the Secchi depth associated with dinoflagellate blooms (Gallegos et al. 1992).

\section{Field measurements}

The Rhode River was sampled at 6 stations at weekly to bi-weekly intervals from 1990 to 2009 . Sampling period usually ranged from early March through mid-December depending on ice and weather conditions or availability of boats, although in some years sampling continued all year, especially early in the series. Stations are designated by their distance from the mouth ( $\mathrm{km}$, positive up estuary) and coincide with those shown by Gallegos et al. (2010), exclusive of Stn 6.2, at which P-E curves were not measured. Measurements on station consisted of profiles of temperature $(T)$, salinity, and dissolved oxygen with a Hydrolab ${ }^{\mathrm{TM}}$ (1990 to 2005) or $\mathrm{YSI}^{\mathrm{TM}}$ 6600 (April 2005 onwards) datasonde, and cosine- 
corrected photosynthetically active radiation (PAR, 400 to $700 \mathrm{~nm}$ ) with a Li-Cor Li-192 underwater quantum sensor. The diffuse attenuation coefficient for PAR, $K_{d}$, was determined by regression of the natural log of PAR against depth. Secchi depth was measured on the sunny side of the boat. Samples for depth-averaged chl a concentration were collected by slowly lowering and raising a Labline ${ }^{\mathrm{TM}} \mathrm{Teflon}^{\mathrm{TM}}$ sampler in less time than required to fill. Samples for P-E parameters, discrete chl $a_{\text {, }}$ and species composition were collected by filling the sampler at the Secchi depth.

\section{Laboratory measurements}

Subsamples for species identification were preserved immediately in the field using $1 \%$ acid Lugol's solution and stored in $125 \mathrm{ml}$ polyethylene bottles until counting. For counting, 1 to $10 \mathrm{ml}$ were settled (minimum $4 \mathrm{~h}$ ) and viewed at a magnification of $512 \times$ under an inverted microscope. Complete identification, counting, and analysis procedures for phytoplankton species composition are given by Gallegos et al. (2010).

Subsamples for chl a analyses were filtered onto Whatman GF/F glass fiber filters immediately upon returning to the laboratory. Filters were extracted in $10 \mathrm{ml}$ of $90 \%$ acetone either immediately or after freezing for $<2 \mathrm{wk}$. Extracted chl a was estimated spectrophotometrically using the wavelengths and equations given by Jeffrey \& Humphrey (1975).

Phytoplankton photosynthesis was measured as ${ }^{14} \mathrm{C}$ uptake using the small volume 'photosynthetron' method of Lewis \& Smith (1983). A $50 \mathrm{ml}$ subsample was inoculated with 0.5 to $2.5 \mu \mathrm{Ci} \mathrm{ml}{ }^{-1} \mathrm{NaH}^{14} \mathrm{CO}_{3}$, depending on phytoplankton biomass. Subsamples of $1 \mathrm{ml}$ were dispensed into 24 lighted and 2 dark $7 \mathrm{ml}$ glass scintillation vials, which were placed in an aluminum block drilled with holes for lighting from below. Samples from 3 stations at a time were incubated for $1 \mathrm{~h}$ at a range of light intensities supplied by a Westinghouse $400 \mathrm{~W}$ metal halide lamp. These lamps have a wide but irregular spectrum (Bubenheim et al. 1988), but $P^{B}{ }_{\max }$ is expected to be relatively insensitive to spectral energy distribution (Pickett \& Meyers 1966, Sathyendranath \& Platt 1989, Lorenzo et al. 2004). Incubations were terminated by the addition of $250 \mu \mathrm{l}$ of $1 \mathrm{~N} \mathrm{HCl}$ and shaking $1 \mathrm{~h}$ to drive off unincorporated ${ }^{14} \mathrm{C}$. Rates of ${ }^{14} \mathrm{C}$ fixation were calculated by the equations of Strickland \& Parsons (1972), using an isotope discrimination factor of 1.06. Various instruments were used to measure the concentration of dissolved inorganic carbon (IC): a Shimadzu TOC5000 (1990 to 1997), a Capni-Con 5 Total $\mathrm{CO}_{2}$ Analyzer (Cameron Instruments, 1998 to 2006), and a Li-Cor 7000 (2007 to 2009). Instruments were calibrated to known solutions before each cruise. IC concentrations were determined by titration (Strickland \& Parsons 1972) whenever instruments were being repaired.

\section{Data analysis}

Parameters were estimated in the P-E relationship (Jassby \& Platt 1976) as

$$
P^{B}(E)=P_{\max }^{B} \tanh \left(\frac{\alpha^{B} E}{P_{\max }^{B}}\right)+R^{B}
$$

where $P^{B}$ is the ${ }^{14} \mathrm{C}$ photosynthesis rate normalized to chl $a, E$ is the photon flux density measured in the incubation vial, $P^{B}{ }_{\text {max }}$ is the maximal photosynthesis rate at light saturation, $\alpha^{B}$ is the slope of the linear portion of the P-E relationship at low light intensities, and the intercept, $R^{B}$, is allowed to be positive or negative to avoid bias in the calculation of $\alpha^{B}$. Parameters were estimated by minimization of squared residuals, except in 2007, when, due to funding limitations, $P^{B}{ }_{\text {max }}$ was estimated from measurements of ${ }^{14} \mathrm{C}$ uptake in 5 vials incubated at light intensities previously found to be light-saturating. Typical magnitudes for the coefficients of variation of the parameters were $10 \%$ for $P^{B}{ }_{\text {max }}$ and $20 \%$ for $\alpha^{B}$. The emphasis of this paper in on analysis of $P^{B}{ }_{\text {max }}$ due to its importance in governing primary production in shallow waters.

Measurements of $P^{B}{ }_{\max }$ and its environmental correlates were analyzed for temporal and spatial variability by general linear modeling (GLM), with month and station as categorical variables, and year was treated both as a categorical variable and as a continuous variable to test for the presence and significance of any long-term trends. Temporal and spatial patterns uncovered by the GLM analysis of measurements were then used as the benchmark for evaluation of physiologically and statistically based models. GLM analyses were performed using the Data Desk 6.1 statistical analysis program.

\section{Physiological models}

Two physiologically based models were examined, one based on carbon balance and the chl:C ratio, and PhotoAcc by Behrenfeld et al. (2002). The con- 
nection between balanced growth rate and photosynthetic rate has been made by several authors (Eppley 1972, Cullen 1990, Cloern et al. 1995) as an energy balance,

$$
\frac{(\mu+r)}{D}=P^{B}(\mathrm{chl}: \mathrm{C})
$$

where $\mu\left(\mathrm{d}^{-1}\right)$ is the carbon-specific growth rate, $r\left(\mathrm{~d}^{-1}\right)$ is the carbon-specific respiration rate, $D\left(\mathrm{~h} \mathrm{~d}^{-1}\right)$ is the photoperiod, chl: $\mathrm{C}$ is the cellular chl $a$ to carbon ratio, and as before, $P^{B}$ is the chlorophyll-specific photosynthetic rate. To estimate growth rate of a mixed-species assemblage, $\mu_{j}$ of the $j$ th taxon were calculated from allometric equations with cell carbon (Tang 1995) calculated from phytoplankton counts and volume estimates (Gallegos et al. 2010),

$$
\mu_{j}=a_{j} C_{j}^{\beta}
$$

where $a_{j}=2.04$ for dinoflagellates and 3.56 for all other taxa, and $\beta=-0.19$ for all taxa (Tang 1995). $\mu$ for the sample was calculated as the carbon-weighted average of the taxa present and scaled for temperature by an exponential factor with a value of 1 at $20^{\circ} \mathrm{C}$ and $Q_{10}$ of 2. Taking this as the balanced growth rate at light-saturation, $P^{B}{ }_{\max }$ was calculated by rearrangement of Eq. (9) of Cloern et al. (1995),

$$
P_{\text {max }}^{B}=\frac{(\mu+0.015)}{0.85 D \times \mathrm{chl}: \mathrm{C}}
$$

where the constants 0.85 (dimensionless) and 0.015 $\left(\mathrm{d}^{-1}\right)$ account for growth rate-dependent and -independent respiratory losses, respectively, and $D$ was taken from a table of daylight hours calculated for the latitude of the Rhode River. Chl:C was calculated from Eq. (15) in Cloern et al. (1995), ignoring the nutrient term,

$$
\begin{aligned}
& \text { Chl:C }=0.003+0.0154 \exp (0.05 T) \\
& \left\{\exp \left(-0.059 \frac{E_{0}}{K_{d} H}\right)\left[1-\exp \left(-K_{d} H\right)\right]\right\}
\end{aligned}
$$

where $E_{0}=$ incident irradiance $\left(\mathrm{mol}\right.$ quanta $\left.\mathrm{m}^{-2} \mathrm{~d}^{-1}\right)$ on the day prior to sampling, $T=$ temperature $\left({ }^{\circ} \mathrm{C}\right)$, and $H=$ station depth (m). This is referred to as the basic balanced growth model. Subsequent analysis (see below) revealed that the temperature sensitivity of Eq. (5) resulted in chl:C that were too low in winter to spring months, resulting in systematic overestimates of $P^{B}{ }_{\max }$. An adjusted balanced growth model was then considered by standardizing Eq. (5) at $25^{\circ} \mathrm{C}$.

Behrenfeld et al. (2002) derived the PhotoAcc model from a consideration of the effects of photoacclimation and nutrient limitation on relative changes in cellular chl a concentrations and photo- synthetic carbon fixation capacity. Their fitted equation for $P^{B}{ }_{\max }$ under nutrient-sufficient conditions was given by

$$
P_{\max }^{B}=\left[0.036+0.3 \exp \left(-3 I_{\mathrm{g}}\right)\right]^{-1}
$$

where $I_{\mathrm{g}}\left(\mathrm{mol}\right.$ quanta $\left.\mathrm{m}^{-2} \mathrm{~h}^{-1}\right)$ is the growth irradiance for acclimation, which they took to be the irradiance at the bottom of the mixed layer. For nutrientdeficient conditions, Eq. (6) was multiplied by a scalar of 0.4 (Behrenfeld et al. 2002). They considered $P_{\max }^{B}$ to be insensitive to temperature above $5^{\circ} \mathrm{C}$. For application in the shallow Rhode River, $I_{\mathrm{g}}$ was calculated as the hourly averaged light reaching the bottom, $\left(E_{0} / 24\right) \exp \left(-K_{d} H\right)$. This is reffered to as the basic PhotoAcc model. Subsequent analysis (see below) revealed that the seasonal pattern calculated by the basic PhotoAcc model was dampened and out of phase with measurements due to positive correlation between $E_{0}$ and $K_{d}$ as a result of high attenuation coefficients in summer (Gallegos et al. 2005). An adjusted PhotoAcc model was then considered using water column-averaged light intensity, $I_{\mathrm{av}}$ in place of the light at the bottom

$$
I_{\mathrm{av}}=\frac{E_{0}}{K_{d} H}\left[1-\exp \left(-K_{d} H\right)\right]
$$

substituting $I_{\mathrm{av}}$ for $I_{\mathrm{g}}$ in Eq. (6). Due to the difference in scale between $I_{\mathrm{av}}$ and $I_{\mathrm{g}}$ it was necessary in the adjusted version to use the nutrient-limited version of PhotoAcc, which multiplies the right hand side of Eq. (6) by 0.4 (Behrenfeld et al. 2002). Other modeling approaches have been elaborated (e.g. Geider et al. 1998), but these examined here could be applied with data at hand, and the need for more complex photoacclimation models has been questioned (Flynn 2003).

\section{Statistical models}

Statistical models for the dependence of $P^{B}{ }_{\text {max }}$ on various environmental correlates were estimated by stepwise linear regression on data transformed to normalize and account for the expected mode of response (Harding et al. 2002). A forward selection procedure was used with a criterion of $2 \%$ increment in adjusted $\mathrm{R}^{2}$ to remain, and the order of trial determined by the rank order of the $t$-statistic in an initial analysis that included all available predictors. The winter months were unevenly sampled in different years due to weather conditions and boat availability. Therefore, the data were additionally analyzed for interannual variability and estimated statistical mod- 
els using data from the month of September, typically the month of the annual maximum in this system. Transformations to achieve normality (KolmogorovSmirnov test) were square root for $P^{B}{ }_{\text {max }}$ and natural logarithm for $T$, chl $a$, and $K_{d}$. No transformations were needed to normalize the IC concentrations or principal component (PC) scores of species abundances. PC scores were computed on $\ln \left(1+\right.$ cells $\left.\mathrm{ml}^{-1}\right)$ of counts data. Further details of the PC analysis and taxa in the species list are given by Gallegos et al. (2010). PAR values averaged over the water column for 1 or $3 \mathrm{~d}$ prior to sampling were tested but were not significant correlates of $P^{B}$ max.

The length of the time series and the density of measurements provide an opportunity to examine the stability of parameter estimates in the statistical models. Once the significant predictors were determined, parameters were estimated for each year, to compare with parameters estimated by each successive year cumulatively, and in both 3 and 5 yr groupings of the data.

\section{RESULTS}

\section{Observed variations}

$P^{B}{ }_{\text {max }}$ in the Rhode River ranged from 0.1 to $21.2 \mathrm{mg}$ $\mathrm{C} \mathrm{mg}^{-1} \mathrm{chl} \mathrm{a} \mathrm{h}^{-1}$ from 1990 to 2009, and averaged $3.5 \pm 2.1(\mathrm{SD}) \mathrm{mg} \mathrm{C} \mathrm{mg}^{-1} \mathrm{chl} \mathrm{a} \mathrm{h}^{-1}$ (Fig. 1A). The expected seasonal pattern was repeated each year, with minimal values in winter and highest values and the most scatter in summer (Fig. 1A,B), such that the lowest values in summer usually overlapped the highest measurements in winter (Fig. 1A). The GLM analysis of $P^{B}{ }_{\text {max }}$ in terms of year, season, and station showed that month (i.e. season) accounted for the greatest amount of the variance (mean square, $\mathrm{MS}=$ $370)$, followed by year $(\mathrm{MS}=79)$, then station $(\mathrm{MS}=$ 22). The seasonal expected value of measured $P^{B}{ }_{\max }$ varied approximately sinusoidally over the year, with a minimum in January and maximum in September (Fig. 1B). Differences among years were apparent as well. For example, more values $>10 \mathrm{mg} \mathrm{C} \mathrm{mg}^{-1} \mathrm{chl} a$ $\mathrm{h}^{-1}$ were observed prior to 1997 (35 of 1419 measurements) compared with the period after 1997 (5 of 1863 measurements; Fig. 1A). Occasional elevated winter minima are evident, for example in 1997 and 2006 to 2008 (Fig. 1A). Treating year as a continuous variable in the GLM revealed a significant $\left(\mathrm{p}<10^{-4}\right)$ downward trend of $-0.042 \mathrm{mg} \mathrm{C} \mathrm{mg}^{-1} \mathrm{chl} \mathrm{a} \mathrm{h} \mathrm{h}^{-1} \mathrm{yr}^{-1}$ (Table 1), which remained statistically significant $\left(\mathrm{p}<10^{-4}\right)$ at $-0.033 \mathrm{mg} \mathrm{C} \mathrm{mg}^{-1} \mathrm{chl} \mathrm{a} \mathrm{h}^{-1} \mathrm{yr}^{-1}$ ignoring
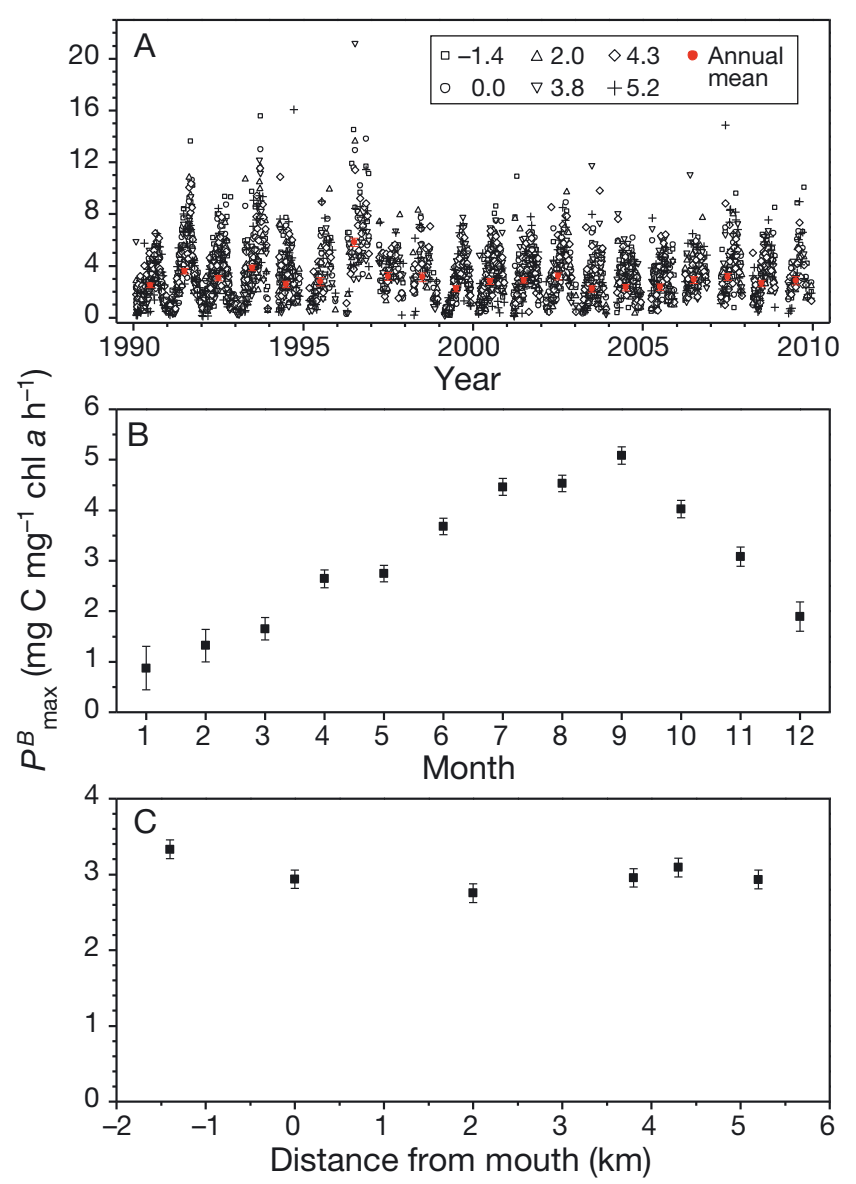

Fig. 1. (A) Measurements of the light-saturated rate of phytoplankton photosynthesis normalized to chlorophyll $a$, $P^{B}{ }_{\max }$ at 6 stations in the Rhode River, Maryland (USA). Annual means (red circles) are plotted at the mid-year. Stations are designated by distance from the sub-estuary mouth in $\mathrm{km}$ (positive up estuary). (B) Seasonal variability of $P^{B}{ }_{\max }$. (C) Spatial variability in measured $P^{B}$ max. Error bars in all are $\pm 2 \mathrm{SE}$

the anomalously high year 1996. This trend was even stronger, $-0.135 \mathrm{mg} \mathrm{C} \mathrm{mg}^{-1} \mathrm{chl} \mathrm{a} \mathrm{h}^{-1} \mathrm{yr}^{-1}$, when the data were selected for the more evenly sampled month of September (Table 1). Spatial variability in measured $P^{B}{ }_{\max }$ was statistically significant (Fig. 1C), though as noted, accounting for less variance than either seasonal or interannual modes. The spatial mean was greatest beyond the mouth outside the Rhode River ( $\mathrm{km}-1.4)$ and lowest $2 \mathrm{~km}$ up estuary of the mouth (Fig. 1C).

\section{Physiological models}

The GLM analysis of $P_{\text {max }}^{B}$ calculated by the physiological models in terms of year, season, and station differed from the analysis of observed $P_{\text {max }}^{B}$ with 
Table 1. Slopes and statistics of the measured or modeled light-saturated rate of phytoplankton photosynthesis normalized to chlorophyll a $\left(P_{\max }^{B}\right)$ and environmental correlates against year as estimated by general linear modeling analysis treating year as a continuous variable. Units of slope are $\mathrm{mg} \mathrm{C} \mathrm{mg}{ }^{-1} \mathrm{chl} \mathrm{a} \mathrm{h}^{-1} \mathrm{yr}^{-1}$ for $P^{B}$ max , and as given for environmental correlates. $T$ : temperature; IC: inorganic carbon; $K_{d}$ : diffuse attenuation coefficient for photosynthetically active radiation; PC: principal component

\begin{tabular}{|c|c|c|c|}
\hline Measured or modeled $P_{\max }^{B}$ & Slope & $t$ & $\mathrm{p}$ \\
\hline Measured $P_{\max }^{B}$ all data & -0.042 & -7.85 & $<10^{-4}$ \\
\hline Measured $P_{\max }^{B}$, September & -0.135 & -6.51 & $<10^{-4}$ \\
\hline Basic balanced growth model & -0.024 & -3.00 & 0.003 \\
\hline Adjusted balanced growth model & -0.013 & -1.71 & 0.088 \\
\hline $\begin{array}{l}\text { Adjusted balanced growth model, } \\
\text { lower estuary }\end{array}$ & -0.006 & -0.74 & 0.459 \\
\hline Basic PhotoAcc model & 0.002 & 0.33 & 0.74 \\
\hline Adjusted PhotoAcc model & 0.005 & 1.17 & 0.24 \\
\hline $\begin{array}{l}\text { Adjusted PhotoAcc model, } \\
\text { lower estuary }\end{array}$ & 0.007 & 1.78 & 0.075 \\
\hline \multicolumn{4}{|l|}{ Stepwise regression model, all data } \\
\hline $\ln (T)$ predictor & 0.003 & 2.58 & 0.01 \\
\hline $\ln (T)$, IC predictors & -0.010 & -4.51 & $<10^{-4}$ \\
\hline All predictors & -0.029 & -8.95 & $<10^{-4}$ \\
\hline \multicolumn{4}{|c|}{ Stepwise regression model, September } \\
\hline IC predictor & -0.068 & -6.12 & $<10^{-4}$ \\
\hline All predictors & -0.166 & -9.41 & $<10^{-4}$ \\
\hline $\ln (T)\left(\mathrm{yr}^{-1}\right)$ & 0.0021 & 3.26 & 0.001 \\
\hline $\mathrm{IC}\left(\mathrm{mg} \mathrm{C} \mathrm{l}^{-1} \mathrm{yr}^{-1}\right)$ & -0.056 & -5.91 & $<10^{-4}$ \\
\hline $\ln (\mathrm{chl} a)\left(\mathrm{yr}^{-1}\right)$ & 0.012 & 5.73 & $<10^{-4}$ \\
\hline $\ln \left(K_{d}\right)\left(\mathrm{yr}^{-1}\right)$ & -0.002 & -1.69 & 0.091 \\
\hline PC $5\left(\mathrm{yr}^{-1}\right)$ & -0.002 & -0.56 & 0.57 \\
\hline PC 4 , September $\left(\mathrm{yr}^{-1}\right)$ & 0.004 & 0.52 & 0.61 \\
\hline
\end{tabular}

station accounting for the greatest amount of variance, followed by month then year for each model. Nevertheless, presentation will follow the order of the analysis of observed data.

\section{Seasonal variability}

The seasonal variability predicted by both physiologically based models was suppressed relative to measurements (Fig. 2A,B). For the basic balanced growth approach (Fig. 2A) this was found to be due to excessive temperature sensitivity of the chl:C ratio (Fig. 3A). The low values of chl:C predicted by Eq. (5) in spring and winter (Fig. 3A, squares), when substituted into the denominator of Eq. (4), produced excessively high values of $P_{\text {max }}^{B}$ thereby dampening the overall predicted seasonal variability. Adjustment of the balanced growth model to standardize the temperature at $25^{\circ} \mathrm{C}$ in Eq. (5) dampened the seasonal variability in chl:C (Fig. 3A, circles) and thereby restored seasonal variability in $P^{B}{ }_{\max }$, albeit with substantial over-prediction in May and June (Fig. 2A, blue triangles).

In predictions by PhotoAcc, the dampening of predicted seasonality was caused by the seasonal covariation of incident light (photoperiod and maximal noon irradiance) with the light attenuation coefficient (Gallegos et al. 2005), causing calculated $I_{\mathrm{g}}$ (Eq. 6, Fig. 3B, squares) to have a local maximum in March with increasing photoperiod and maximum irradiance, and a local minimum in August due to seasonally high $K_{d}$. Adjustment of the PhotoAcc calculation to use averaged light in the water column for growth irradiance (Fig. 3B, circles) restored unimodal seasonality in $P^{B}{ }_{\text {max }}$ with a maximum in June (Fig. 2B, blue triangles), although predictions were substantially out of phase with observations. Additionally, when using water column-averaged light in PhotoAcc, it was necessary to use the nutrientlimited form to achieve an appropriate scale in the calculations.

Subsequent analysis of spatial variability (see below) indicated that over predictions by both models could be driven by calculations for the shallow upper estuary stations where shallow depths resulted in lower calculated chl:C (Eq. 5) and higher $I_{\mathrm{av}}$ (Eq. 7). The data were therefore reanalyzed for seasonal and interannual variability based on stations from the lower estuary alone $(\mathrm{km}<2.0)$ (Fig. 2A,B, green triangles). Analyzed in this way, the predictions of monthly mean $P^{B}{ }_{\text {max }}$ by the adjusted balanced growth approach closely matched monthly means from January through July, but under predicted observed monthly means from August through November (Fig. 2A, green triangles). Restricting analysis of the adjusted PhotoAcc model to the lower estuary stations reduced the degree of over prediction from January through June, but prediction remained out of phase with observations (Fig. 2B, green triangles).

\section{Interannual variability}

The basic balanced growth model with temperature sensitivity in chl:C overestimated annual mean $P^{B}{ }_{\text {max }}$ in all years except 1996 (Fig. 2C, red circles). Removal of temperature sensitivity in chl: $\mathrm{C}$ reduced the degree of over prediction and resulted in unbiased overall means with respect to measurements ( $p=0.30$; Fig. 2C, blue triangles). Restriction of the analysis to lower estuary stations slightly lowered the calculated annual means but without introducing significant bias (Fig. 2C, green triangles). There was 

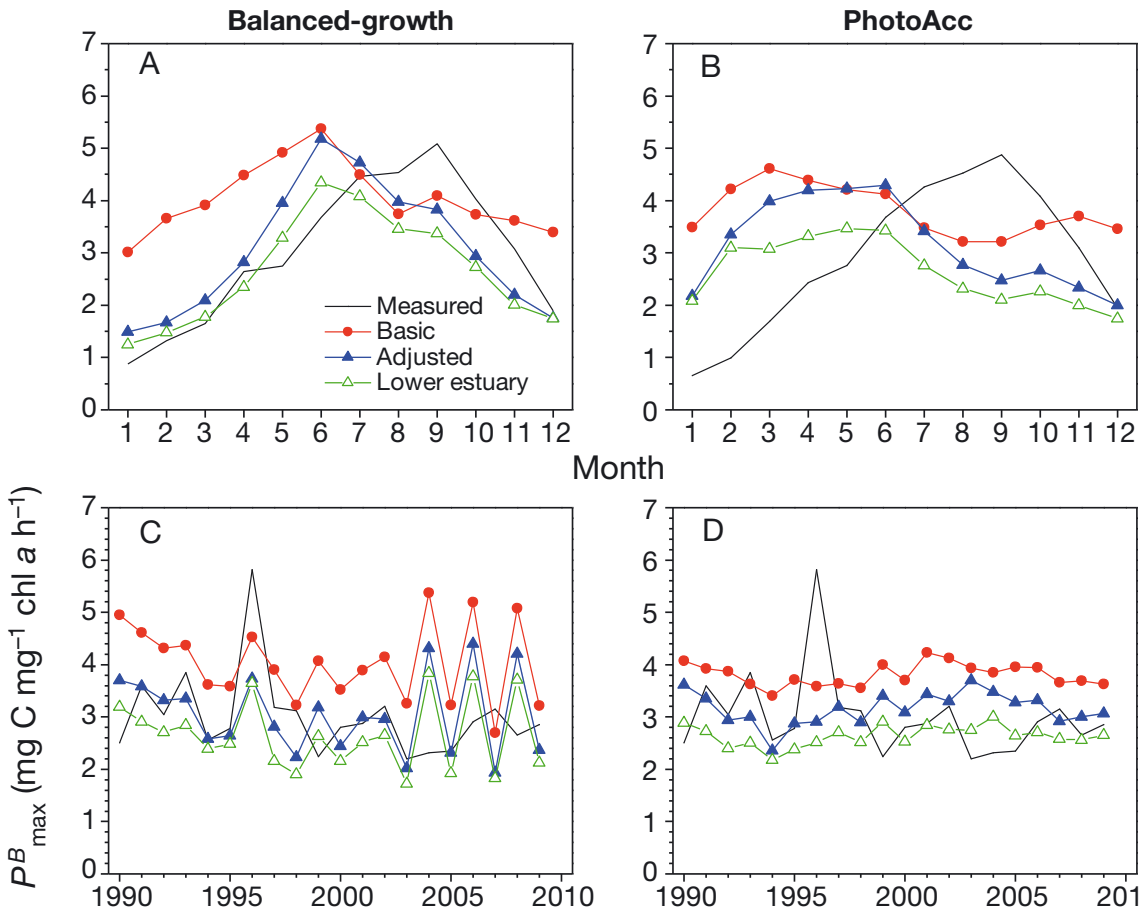

Month
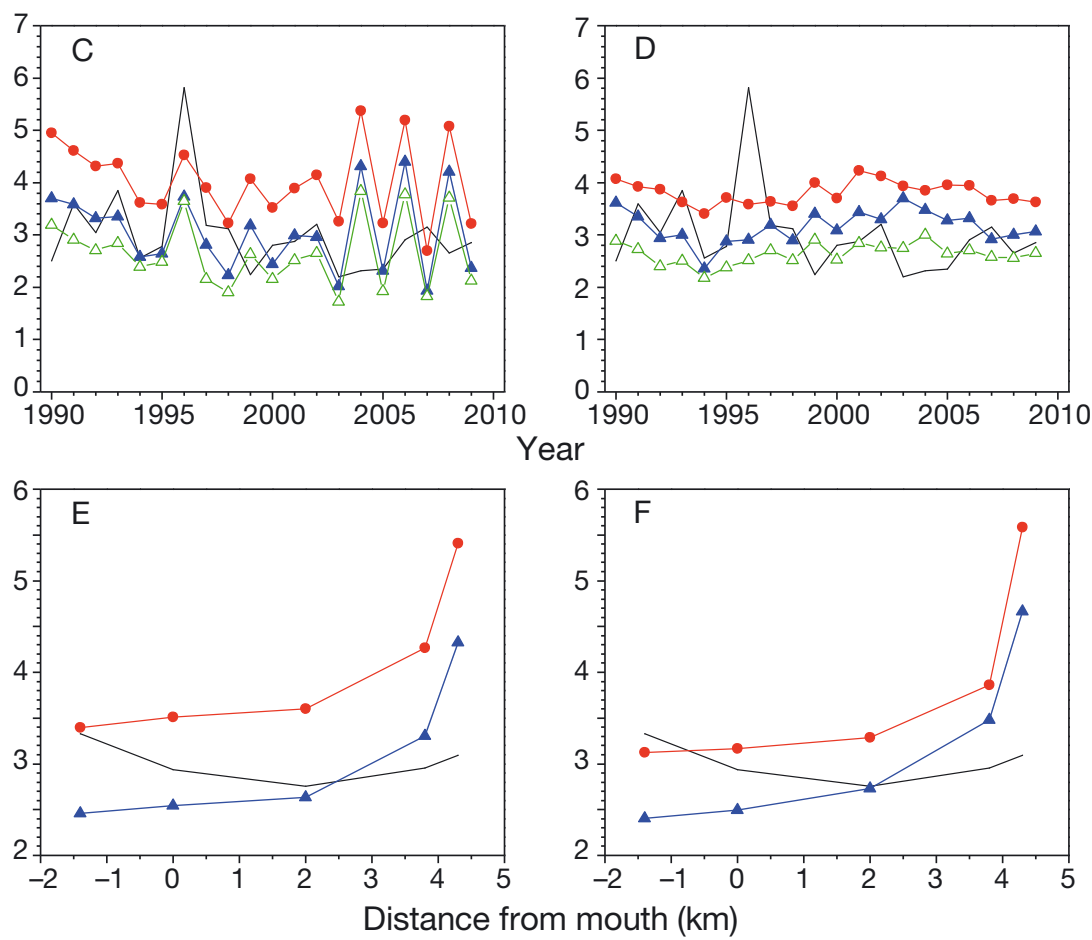

Fig. 2. Comparison of measured (black lines) and physiological model-estimates of components of variation in $P^{B}{ }_{\text {max }}(\mathrm{A}, \mathrm{C}, \mathrm{E})$ are based on the balanced growth approach (Eqs. 2-5) and $(B, D, F)$ are based on the photoacclimation approach (Eq. 6). Red circles are model equations as originally published; blue triangles are based on adjustments described in 'Materials and methods' to resolve discrepancies; and green triangles are model calculations selected for optically deeper lower estuary stations $(<2 \mathrm{~km})$. $(\mathrm{A}, \mathrm{B})$ seasonal variability; $(\mathrm{C}, \mathrm{D})$ interannual variability; $(\mathrm{E}, \mathrm{F})$ spatial variability

an intriguing tendency for predictions of the adjusted balanced growth model to track measured annual means from 1995 to 2003 ; however, overall the 2 series were uncorrelated $\left(R^{2}=0.054, p>0.13\right)$, due in part to large year-to-year oscillations in model annual means from 2003 onwards (Fig. 2C) not present in the measurements. Treating year as a continuous variable in the GLM gave a significantly negative slope for the basic balanced growth model, but insignificant slopes for the adjusted models that better fit the data (Table 1).
Annual means predicted by the basic PhotoAcc model (Fig. 2D, red circles) were higher than measured values in all but 2 years, and years were significantly higher overall $(\mathrm{p}<$ 0.001). The adjusted PhotoAcc calculations were closer to observed annual means but mostly higher, though not significantly so $(\mathrm{p}>0.1$; Fig. $2 \mathrm{D}$, blue triangles). Restricting analysis of the adjusted PhotoAcc model to lower estuary stations brought the level of the predictions closer still to observations (Fig. 2D, green triangles). No version of the PhotoAcc model had a significant slope when treating year as a continuous variable in the GLM analysis (Table 1).

\section{Spatial variability}

Both physiologically based models over predicted the degree of variability attributable to location as a result of the gradient in depth and light attenuation coefficient (Fig. 2E,F). Adjustment of the balanced-growth model by removal of the temperature dependence of chl:C reduced the overall overestimation by the basic balanced growth model (Fig. 2E), but systematically underestimated $P^{B}{ }_{\max }$ down estuary of $\mathrm{km} 2.0$ and overestimated at upper stations. With PhotoAcc, the switch from bottomlight to water column-averaged light resulted in a similar systematic deviation as with the balanced growth model (Fig. 2F). In both cases, it is evident from the measurements that longitudinal mixing prevents adaptation of $P^{B}{ }_{\max }$ to the local optical depth. The appropriate scale is achieved in the model calculations for the station at $2.0 \mathrm{~km}$.

Neither physiologically based model, even as adjusted and selected for lower estuary stations, produced a good fit with individual measurements (Fig. 4). The adjusted balanced growth model predicted the overall range and mean of measurements (Fig. 4A), but the coefficient of determination was low $\left(R^{2}=0.031\right)$. The average of the predictions by the adjusted PhotoAcc model matched that of the 

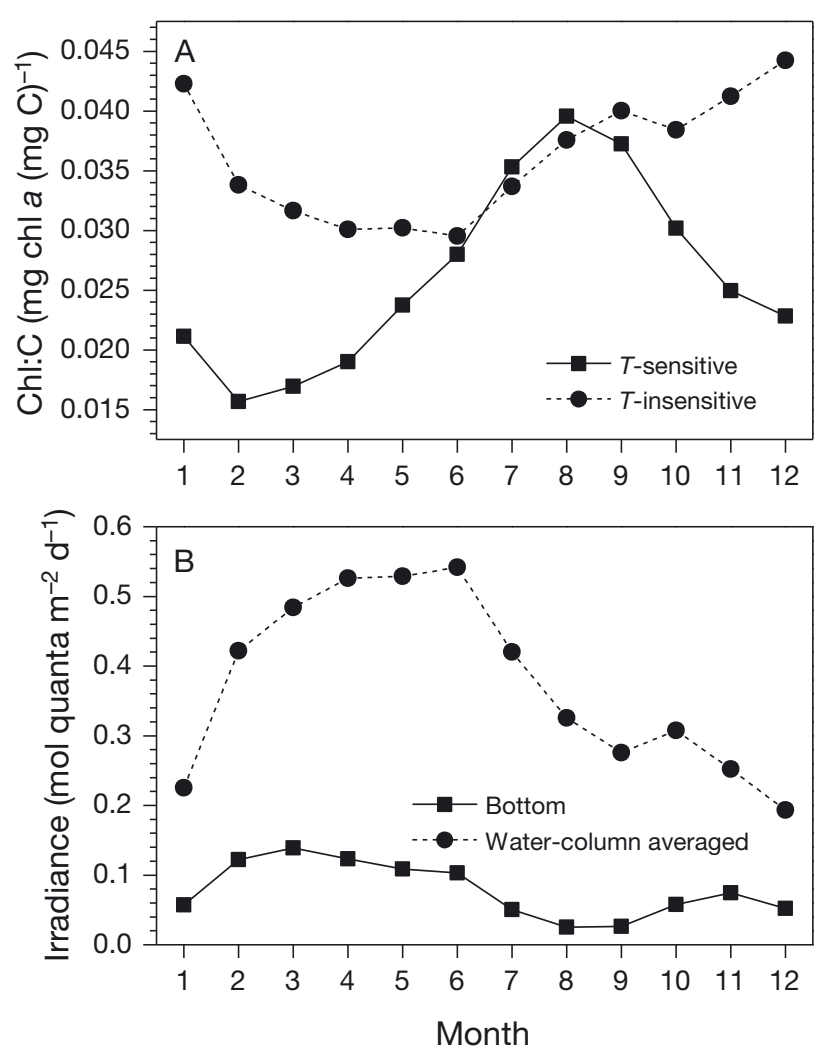

Fig. 3. (A) Seasonal variation in the ratio of phytoplankton cellular chlorophyll a ( $\mathrm{chl} \mathrm{a)} \mathrm{to} \mathrm{carbon} \mathrm{calculated} \mathrm{by} \mathrm{Eq.} \mathrm{(5)}$ as published (squares and solid line) and without the temperature $(T)$ sensitivity term as modified here (circles and dashed line). The low values of chl:C in winter months caused overestimates in $P^{B}{ }_{\text {max }}$ from January through June (cf. Fig. 2A). The adjusted balanced growth model was based on chl:C ratios calculated without temperature sensitivity (see 'Materials and methods'). (B) Seasonal variation of light available at the bottom (squares and solid line) and water-column averaged light (circles and dashed line), used in calculation of $P^{B}{ }_{\max }$ in the PhotoAcc model. Using light at the bottom caused calculations to be out of phase with measurements due to maximum from February to April and minimum in August and September. Use of water column averaged light in the adjusted PhotoAcc model improved phasing, but required use of the nutrient-limited formulation of the model (see 'Materials and methods')

measurements (Fig. 4B), but PhotoAcc failed to predict the overall range of measurements and the coefficient of determination was likewise low $\left(\mathrm{R}^{2}<0.001\right)$.

\section{Statistical models}

\section{Environmental correlates}

Temperature and IC were the strongest environmental correlates of $P^{B}{ }_{\max }$ although there was much
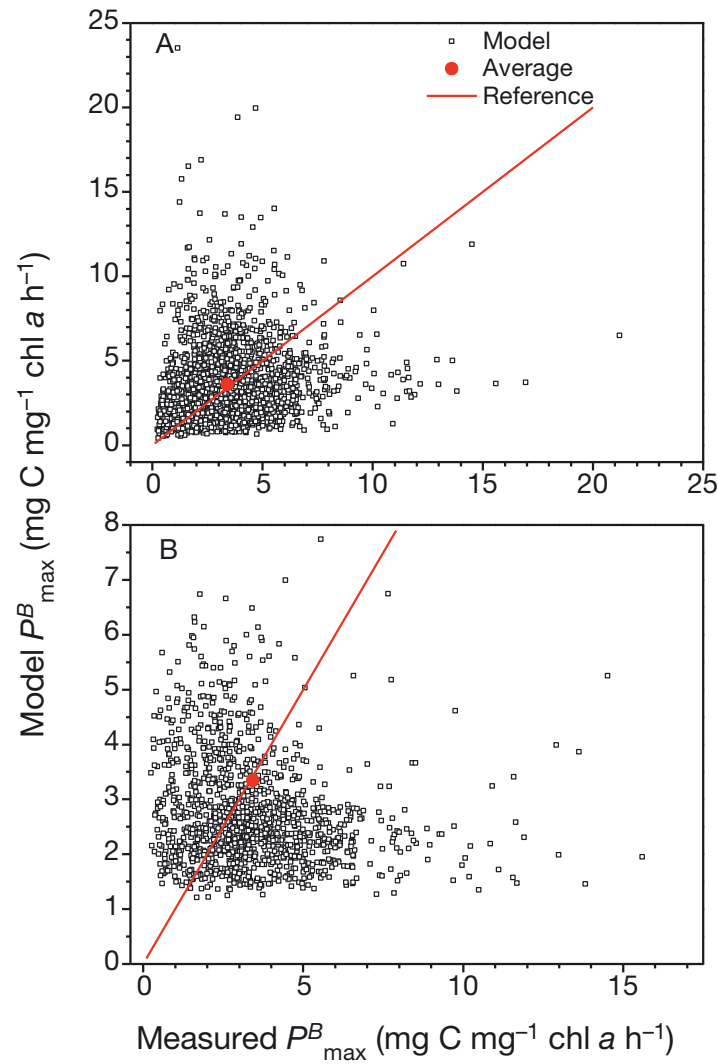

Fig. 4. Comparison of $P^{B}{ }_{\max }$ calculated by physiologically based models with measurements: (A) balanced growth model $_{i}(\mathrm{~B})$ PhotoAcc model. Red lines denote 1:1 correspondence, and red circles are overall means of modeled and measured values. Fewer points are available for (B) because data were selected for temperature $\geq 5^{\circ} \mathrm{C}$ to conform with conditions of the model derivation

scatter in both relationships (Fig. 5A,B). An exponential relationship provided an approximate upper bound to the temperature response of $P^{B}{ }_{\max }$ (Fig. 5A). The stepwise regression of square root-transformed $P^{B}{ }_{\text {max }}$ against appropriately transformed environmental correlates revealed 5 significant predictors (Table 2), with an overall coefficient of determination of 0.45 (Table 2, Fig. 6A). The same variables were statistically significant $\left(\mathrm{p}<10^{-4}\right)$ predictors without transformation, but the statistical fit with the transformed variables was superior to the fit with untransformed variables $\left(\mathrm{R}^{2}=0.37\right)$ for reasons given previously (Harding et al. 2002). Temperature and IC explained $40 \%$ of the variability, with the remaining 3 factors, $\ln (\mathrm{chl} a), \ln \left(K_{d}\right)$, and PC5, accounting for another $5 \%$. Selecting the data for September eliminated $T$ as a factor due to the limited range observed in a single month, and resulted in substitution of PC4 species component for PC5 (Table 2). The regression on September data explained $54 \%$ of the variance 

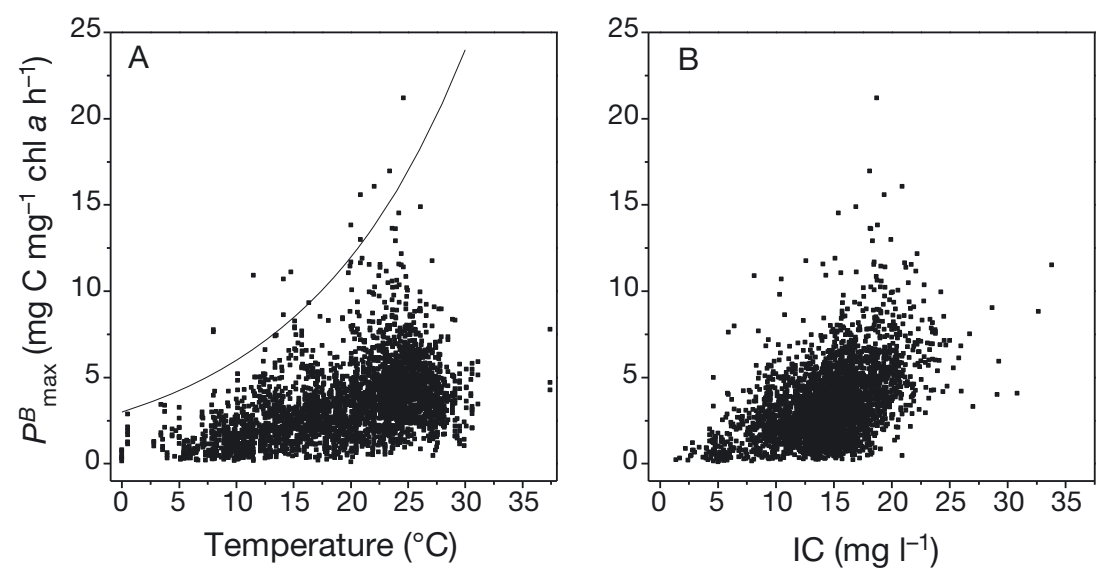

Fig. 5. Relationship of measured $P^{B}{ }_{\max }$ to (A) temperature and (B) the concentration of inorganic carbon (IC). Line in (A) is an empirical approximate upper bound exponential relationship with a $Q_{10}$ of 2
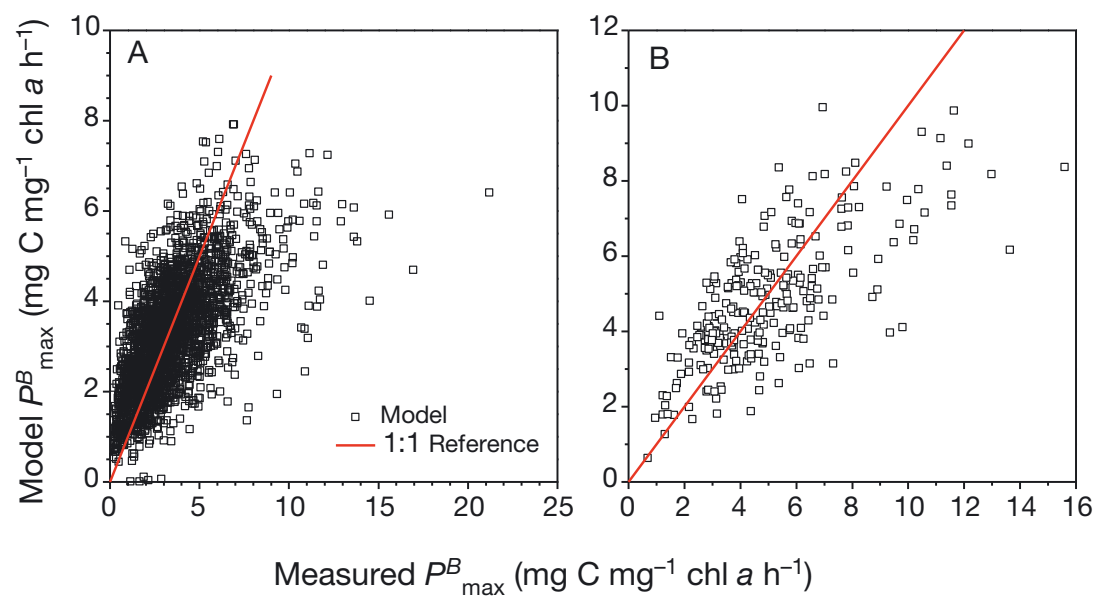

Fig. 6. Comparison of $P^{B}{ }_{\max }$ calculated by statistically based models with measurements: (A) all data; (B) September data, which were sampled more evenly throughout the series. Red lines denote 1:1 correspondence peaked between July and August, earlier than the measured maximum (Fig. 7A, crosses). Inclusion of IC moved the modeled maximum to September (Fig. 7A, open circles). Inclusion of the remaining significant predictors made only fine adjustments to the predictions using only $T$ and IC, mostly in the first 2 mo of the year (Fig. 7A, triangles).

\section{Interannual variability}

The stepwise regression model with $T$ as the only predictor captured very little of the variability in interannual means, varying only from 2.69 to $2.99 \mathrm{mg} \mathrm{C} \mathrm{mg}^{-1} \mathrm{chl} \mathrm{a} \mathrm{h}^{-1}$ compared with an observed range from 2.5 to $5.8 \mathrm{mg} \mathrm{C} \mathrm{mg}^{-1} \mathrm{chl} \mathrm{a} \mathrm{h}^{-1}$ (Fig. 7B). Treating year as a continuous variable with $T$ as the only predictor yielded a significantly positive slope (Table 1), contrary to measurements. With the exception of 1996, inclusion of IC improved prediction of annual means, with predictions of annual means ranging from 2.08 to $3.56 \mathrm{mg}$ $\mathrm{C} \mathrm{mg}^{-1} \mathrm{chl} \mathrm{a} \mathrm{h}^{-1}$. Including IC in the regression resulted in a negative slope of $P_{\text {max }}^{B}$ against year when treating year as a continuous variable in the GLM (Table 1). Inclusion of all significant predictors further improved predictions of annual overall (Fig. 6B), with IC alone accounting for $27 \%$, and the other 4 variables accounting for more of the remaining variance than in the complete data set. The overall range of values observed in the month of September ranged from the 5 th to $>99$ th percentile of all observed values (cf. Fig. 6A,B).

\section{Seasonal variability}

The GLM analysis of the stepwise regression model revealed the same relative ranking of the temporal and spatial components as the observations, i.e. seasonal (MS = 671) was the greatest, followed by interannual (MS = 57) and spatial (MS =6). The regression model with $T$ as the only predictor captured much of the seasonal pattern, except that the prediction means, but no combination of variables predicted the anomalously high values of 1996 (Fig. 7B). Treating year as a continuous variable in the GLM with all significant predictors resulted in a negative slope of $P^{B}$ max with year, although the magnitude was about $30 \%$ lower than the observed slope (Table 1 ).

$P_{\text {max }}^{B}$ values averaged for the month of September ranged from 2.62 to $7.97 \mathrm{mg} \mathrm{C} \mathrm{mg}^{-1} \mathrm{chl} \mathrm{a}^{-1} \mathrm{~h}^{-1}$. That is, substantial interannual variability remained in measured $P^{B}{ }_{\text {max }}$ after restricting the analysis to eliminate possible bias due to uneven sampling of winter months (Fig. 7C). IC alone accounted for $46 \%$ of the interannual variance in $P^{B}$ max averaged for September, while inclusion of all significant predictors improved the overall range of predicted September means (2.59 to $7.82 \mathrm{mg} \mathrm{C} \mathrm{mg}^{-1} \mathrm{chl} \mathrm{a} \mathrm{h}^{-1}$ ) and increased the explained interannual variance to $63 \%$ (Fig. 7C). The 
Table 2. Coefficients in multiple regression of square root of $P^{B}{ }_{\max }$ against transformed environmental correlates, with different groupings of the data. ns: not significant ( $>0.05)$, na: not available, $T$ : temperature; IC: inorganic carbon; $K_{d}$ : diffuse attenuation coefficient for photosynthetically active radiation; PC: principal component

\begin{tabular}{|c|c|c|c|c|c|c|c|c|}
\hline \multirow{2}{*}{ Data selection } & \multirow[b]{2}{*}{ Intercept } & \multirow[b]{2}{*}{$\ln (T)$} & \multirow[b]{2}{*}{$\mathrm{IC}$} & \multirow{2}{*}{\multicolumn{2}{|c|}{$\begin{array}{ll} & \text { Coefficient } \\
\ln (\operatorname{chl} a) & \ln \left[K_{d}\right]\end{array}$}} & \multirow[b]{2}{*}{$\mathrm{PC} 4$} & \multirow[b]{2}{*}{ PC5 } & \multirow[b]{2}{*}{$\mathrm{R}^{2}$} \\
\hline & & & & & & & & \\
\hline All years, all months & 0.174 & 0.470 & 0.0544 & -0.226 & 0.376 & ns & -0.078 & 0.450 \\
\hline All years, September & 1.938 & ns & 0.0858 & -0.459 & 0.401 & -0.151 & -0.084 & 0.540 \\
\hline 1990 & 0.878 & 0.260 & 0.0417 & -0.216 & 0.446 & ns & ns & 0.446 \\
\hline Cumulative 1990 to 1991 & 0.029 & 0.391 & 0.0669 & -0.166 & 0.458 & ns & -0.058 & 0.554 \\
\hline 1992 & -0.183 & 0.388 & 0.0602 & -0.061 & 0.391 & ns & -0.060 & 0.483 \\
\hline 1993 & 0.195 & 0.428 & 0.0513 & -0.176 & 0.460 & ns & -0.104 & 0.513 \\
\hline 1994 & 0.265 & 0.418 & 0.0481 & -0.183 & 0.422 & ns & -0.098 & 0.447 \\
\hline 1995 & 0.351 & 0.410 & 0.0438 & -0.192 & 0.439 & ns & -0.104 & 0.439 \\
\hline 1996 & 0.366 & 0.466 & 0.0504 & -0.271 & 0.451 & ns & -0.096 & 0.440 \\
\hline 1997 & 0.377 & 0.455 & 0.0495 & -0.257 & 0.432 & ns & -0.091 & 0.427 \\
\hline 1998 & 0.269 & 0.475 & 0.0510 & -0.247 & 0.418 & ns & -0.079 & 0.461 \\
\hline 1999 & 0.199 & 0.457 & 0.0580 & -0.245 & 0.414 & ns & -0.082 & 0.469 \\
\hline 2000 & 0.089 & 0.467 & 0.0572 & -0.207 & 0.388 & ns & -0.088 & 0.470 \\
\hline 2001 & 0.117 & 0.461 & 0.0577 & -0.206 & 0.379 & ns & -0.088 & 0.463 \\
\hline 2002 & 0.086 & 0.466 & 0.0569 & -0.203 & 0.383 & ns & -0.092 & 0.468 \\
\hline 2003 & 0.100 & 0.476 & 0.0559 & -0.214 & 0.392 & ns & -0.085 & 0.468 \\
\hline 2004 & 0.122 & 0.457 & 0.0555 & -0.219 & 0.392 & ns & -0.079 & 0.462 \\
\hline 2005 & 0.140 & 0.472 & 0.0557 & -0.224 & 0.403 & ns & -0.079 & 0.462 \\
\hline 2006 & 0.131 & 0.475 & 0.0557 & -0.222 & 0.393 & ns & -0.078 & 0.455 \\
\hline 2007 & 0.137 & 0.474 & 0.0555 & -0.222 & 0.381 & ns & -0.080 & 0.451 \\
\hline 2008 & 0.174 & 0.470 & 0.0544 & -0.226 & 0.376 & ns & -0.078 & 0.450 \\
\hline $2009^{a}$ & 0.082 & 0.494 & 0.0559 & -0.227 & 0.371 & ns & $\mathrm{n} / \mathrm{a}$ & 0.430 \\
\hline
\end{tabular}

slope of $P^{B}{ }_{\max }$ on year, with year treated as a continuous variable in the GLM and data selected for September, was significantly negative with a magnitude about $20 \%$ greater than the observed slope (Table 1).

\section{Spatial variability}

As indicated above, the spatial means of observed $P_{\text {max }}^{B}$ varied only from 2.7 to $3.3 \mathrm{mg} \mathrm{C} \mathrm{mg}^{-1} \mathrm{chl} \mathrm{a} \mathrm{h}^{-1}$ (Fig. 1C), and the spatial pattern of that variability was not captured by any combination of tested predictors in the statistical models (not shown).

\section{Temporal stability of parameters}

The coefficient multiplying $\ln (T)$ in the statistical model on transformed data varied by more than a factor of 6 when the regression was run on individual years (Table 2, Fig. 8A, filled squares). Analyzed by adding successive years to the analysis, the coefficient first came within $10 \%$ of its final value after including the 7 th year of measurements, and remained within $5 \%$ of its final value after the 13th year (Fig. 8A, line). Performing the regressions on data grouped in sequential 3 and 5 yr clusters reduced the range of calculated coefficients, with estimates ranging from 12 to $38 \%$ of the final estimate for 3 yr clusters, and 9 to $15 \%$ for 5 yr clusters (Fig. 8A).

A similar degree of variability as with the coefficient for $\ln (T)$ was observed in the coefficient multiplying IC when running the regression on individual years (Fig. 8B). The coefficient was within $10 \%$ of its final value after $7 \mathrm{yr}$, and remained within $5 \%$ of its final value from $10 \mathrm{yr}$ onwards (Fig. 8B). Estimates obtained from 3 and 5 yr clusters of the data ranged from 1 to $50 \%$ and from 1 to $25 \%$ of the final value, respectively. Coefficients of determination of the regressions based on individual years ranged from 0.15 to 0.78 , with 12 of the 20 years exceeding the cumulative value (Fig. 8C).

\section{DISCUSSION}

\section{Physiological models}

A reliable physiologically based model of P-E parameters is desirable for driving ecosystem models, especially in the context of climate change, 


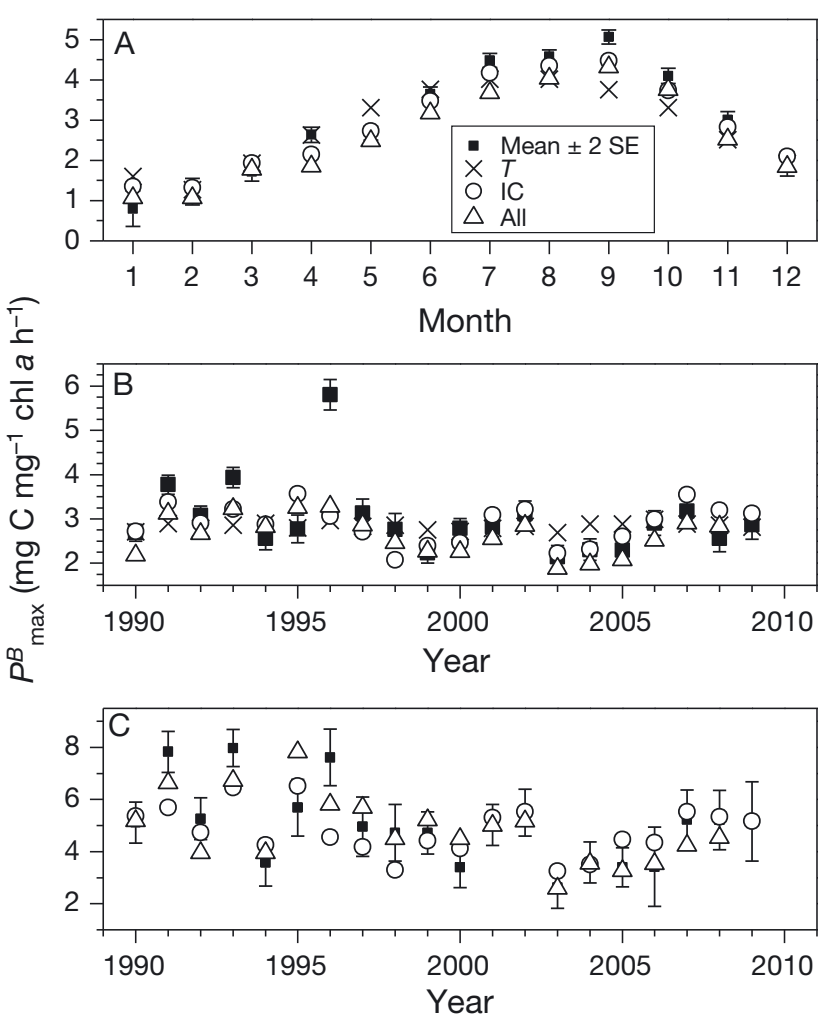

Fig. 7. (A) Seasonal and (B) interannual variation of measured $P^{B}{ }_{\max }$ compared with statistical model calculations with successive addition of significant predictors, and symbols as defined in (A). (C) as for (B), but for September data only. Temperature was not a significant predictor for September data. $T$ : temperature; IC: inorganic carbon

wherein the goal of the analysis is to predict the response to altered future conditions from a mechanistic understanding of the dependencies. The 2 physiological models tested here captured the overall average of measured $P^{B}{ }_{\text {max }}$ of the system, but did not successfully predict individual observations (Fig. 4). Nevertheless, insight into factors controlling $P^{B}{ }_{\max }$ may be gained by examining modes of failure and causes of model deficiencies.

PhotoAcc had some computational characteristics that are not appropriate to this system. For example, the minimum $P_{\text {max }}^{B}$ obtainable with PhotoAcc (nutrient-limited formulation) is $1.19 \mathrm{mg} \mathrm{C} \mathrm{mg}^{-1} \mathrm{chl} \mathrm{a} \mathrm{h}^{-1}$, while many observations were lower than that (Figs. 1A \& 4B). Also, the nutrient-limited version has a maximum $P^{B}{ }_{\max }$ of $11.1 \mathrm{mg} \mathrm{C} \mathrm{mg}^{-1} \mathrm{chl} \mathrm{a} \mathrm{h}^{-1}$, so that some use of the nutrient saturated formulation is needed to capture the whole range of observed values. In some systems, the rate of supply of limiting nutrients may contribute to the prediction of $P^{B}{ }_{\max }$ such as in a stratified ocean in which the distance to the nutracline is an index of the rate of nitrogen sup-
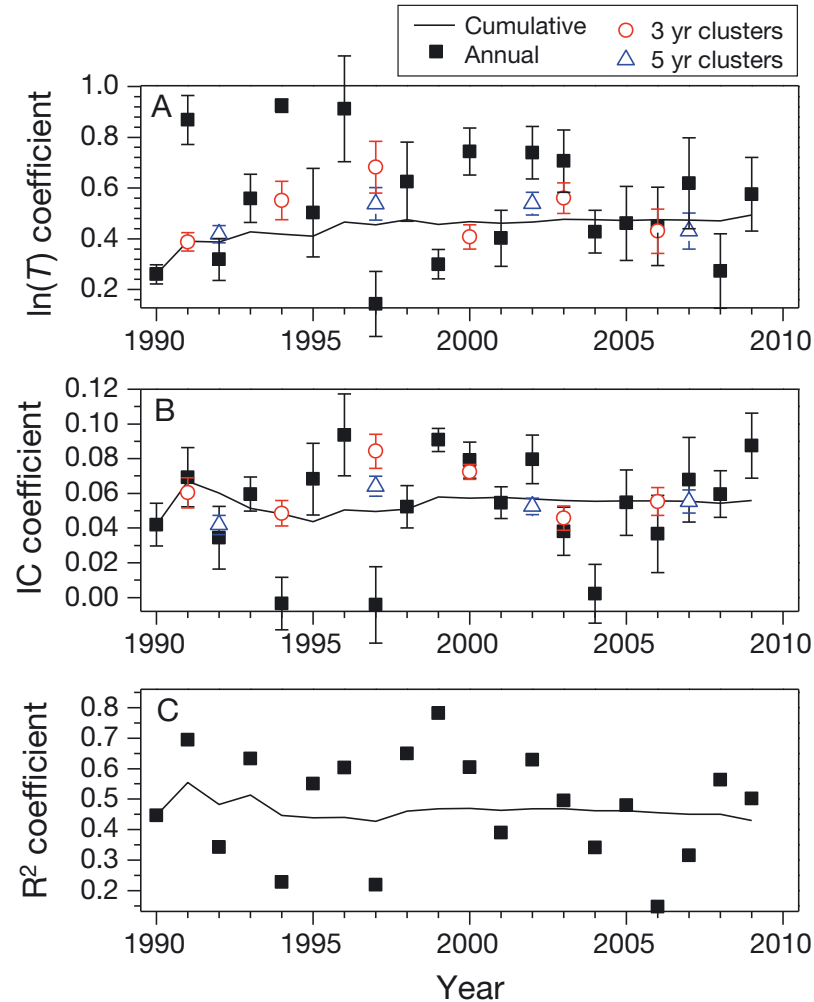

Fig. 8. Coefficients in statistical models for $P^{B}{ }_{\max }$ in relation to (A) temperature $(T)$, and (B) inorganic carbon (IC) concentration, calculated on different temporal groupings of the data shown in the legend. Points for 3 and 5 yr clusters are plotted at the middle year used in the calculation. For the data transformations used, a coefficient in (A) of 0.61 would correspond to a $Q_{10}=2$. (C) Coefficient of determination calculated on individual years (squares) or cumulative addition of successive years (line). Error bars in (A) and (B) are $\pm 1 \mathrm{SE}$ of the coefficients

ply (Bouman et al. 2005). Considering that phytoplankton growth depends on internal nutrient stores, and that in a shallow estuary such as the Rhode River episodic nutrient inputs may come from runoff, the atmosphere, or benthic release, the prospect of anticipating transitions from nutrient-limited to nutrientsaturated states in such a complex system is weak.

It is not surprising that the balanced growth approach would not predict individual observations. There is considerable scatter in the allometric relationships used to calculate growth rates from phytoplankton counts (Tang 1995) as well as in the prediction of chl:C (Cloern et al. 1995). Furthermore, in situ growth in highly dynamic systems may frequently be unbalanced (Cullen 1990). Additional uncertainties are associated with phytoplankton counts, assignment of geometric shapes, and carbon conversions (Strathmann 1967, Hillebrand et al. 1999). In spite of these difficulties, the balanced growth approach cap- 
tured the overall mean and range of observations (Fig. 4A), and the seasonal pattern for the first half of the year (Fig. 2A).

The tendency for both physiologically based models to over emphasize spatial effects (Fig. 2E,F) demonstrates that longitudinal mixing in the Rhode River is too rapid and distances too short for the phytoplankton to become acclimated to the optical depths at the sampling sites, especially in the upper estuary. Predictions matched the spatial means at $2.0 \mathrm{~km}$ (Fig. 2E,F), which has a depth of $3 \mathrm{~m}$ and average optical depth $\left(K_{d} H\right)$ of 4.1 (dimensionless). Jordan et al. (1991a) estimated that the exchange coefficient between the lower and upper Rhode River was $0.4 \mathrm{~d}^{-1}$, suggesting that the time constant for acclimation (Lewis et al. 1984) would be less than this for horizontal mixing to dominate over acclimation.

Failures of the physiologically based models also give some insight into the role of temperature in governing $P^{B}{ }_{\max }$ in the Rhode River. PhotoAcc ignores temperature effects above $5^{\circ} \mathrm{C}$ and attributes all acclimation to light and nutrients (Behrenfeld et al. 2002). The resulting predicted $P^{B}{ }_{\max }$ values seasonally were out of phase with observations, being too high in winter-spring and too low in summer-fall (Fig. 2B), indicating that direct effects of temperature up to $25^{\circ} \mathrm{C}$ on $P^{B}{ }_{\text {max }}$ cannot be ignored (Fig. 5A). The balanced growth approach incorporates direct effects of temperature on the calculated maximum growth rate, and as originally formulated, on the chl:C ratio. This latter effect of reducing chl:C at low temperature counteracts the light-dependent seasonal tendency for chl: $\mathrm{C}$ to be high in winter-spring when photoperiod is short and incident intensity is low (Fig. 3A). It was necessary, therefore, to eliminate the temperature dependency of chl:C to maintain the appropriate seasonality in the model calculations. Geider (1987) found relative insensitivity of $\mathrm{chl}: \mathrm{C}$ to temperature in some species, and seasonal species replacements may reduce the $T$ sensitivity of chl:C. Neither physiological modeling approach, however, predicted the seasonal asymmetry of $P^{B}{ }_{\max }$ with respect to temperature.

\section{Environmental covariates}

The relationship of $P^{B}$ max with temperature in the Rhode River was similar to observations in other estuaries (Pennock \& Sharp 1986, Lohrenz et al. 1994), having an approximate upper bound described by an exponential relationship, and much scatter below the curve, especially at higher temper- atures (Fig. 5A). Temperature accounted for very little of the interannual variability in $P^{B}{ }_{\max }$ (Fig. 7B), and in fact, the trend in the statistical model with $T$ as the only predictor was in the opposite direction of measurements (Table 1). Temperature measured on sampling cruises on the Rhode River has increased at a rate of $0.036^{\circ} \mathrm{C} \mathrm{yr}^{-1}$ (Gallegos et al. 2010), but other factors appear to dominate the effect on $P^{B}{ }_{\max }$.

Inclusion of IC in the regression model captured the timing of the seasonal maximum in $P^{B}{ }_{\max }$ (Fig. 7A), much of the interannual variability (Fig. $7 \mathrm{~B}, \mathrm{C}$ ), and the direction of the long-term trend (Table 1). There is precedence for the finding that IC was a significant predictor of $P^{B}{ }_{\text {max }}$ in the Rhode River. Loftus et al. (1979) measured the IC saturation kinetics of natural populations from the Rhode River on 6 occasions and found that the half-saturation constant, $K_{c}$ averaged 0.55 (range 0.29 to 0.77 ) $\mathrm{mM} \mathrm{C}$ (average 6.65 and range 3.48 to $9.24 \mathrm{mg} \mathrm{Cl}^{-1}$ ). They found that addition of IC as bicarbonate to incubation bottles stimulated ${ }^{14} \mathrm{C}$ uptake by up to 2.5 -fold (Loftus et al. 1979). For IC concentrations ranging from 1.4 to $26 \mathrm{mg} \mathrm{C}^{-1}$ in the measurements reported here, the factor expressing the limitation of photosynthesis by $\mathrm{IC}, \mathrm{IC} /\left(K_{C}+\mathrm{IC}\right)$, would have a typical value of 0.68 (dimensionless) and could be as low as 0.13 .

Limitation by IC may partially account for values of $P^{B}{ }_{\text {max }}$ lower than observed at comparable temperatures in some other coastal systems with stronger marine connections than the Rhode River (e.g. Harrison \& Platt 1980). In the Rhode River, there was a positive, albeit weak $\left(R^{2}=0.28\right)$, dependence of IC on salinity, but salinity was not retained in the stepwise regression analysis as an environmental predictor of $P^{B}{ }_{\max }$. Similarly, there was a weak $\left(R^{2}=0.18\right)$ negative correlation between annual mean IC and annual mean freshwater flow by the Susquehanna River, the principal freshwater source to upper Chesapeake Bay (Malone et al. 1988, Harding 1994). In a riverdominated estuary there is potential for flow-related variability in IC, apart from atmospheric trends, that would not be expected in a more coastal dominated system.

One advantage of a long record of $P^{B}{ }_{\text {max }}$ measurements is that it spans periods of suspected changes in climate regimes (Peterson \& Schwing 2003), of which marine plankton are sometimes very sensitive indicators (Hays et al. 2005). Climate may also directly affect the environmental correlates of $P^{B}{ }_{\max }$ identified here, especially those dependent on flow. Previous research in Chesapeake Bay, however, has indicated that synoptic climatology is a more sensitive indicator of regional climate effects than large-scale ocean-atmospheric indices such as the North Atlantic 
Oscillation, Pacific Decadal Oscillation, or El NiñoSouthern Oscillation (Miller et al. 2006, Miller \& Harding 2007), and that patterns in synoptic climatology have been less clear than the large-scale indices. Out of 20 weather patterns shown to predict $54 \%$ of the variability in spring flow of the Susquehanna River, only 1 displayed a long-term trend over the period from 1950 to 2002 (Kimmel et al. 2009). Given the magnitude of correlations between flow and IC indicated above and the strength of association with $P^{B}{ }_{\max }$ considerable time would be required for anticipated effects of increased concentrations of IC through changes in flow to become evident in measurements of $P^{B}{ }_{\text {max }}$.

An indicator of species composition was retained in the stepwise regression analysis in this study, although the predictive power was low (Table 2). Different species PC scores were retained depending on whether the data were analyzed for the entire year (PC5) or for the month of September (PC4). The eigenvectors for the 2 components share some features in common (Table 3), being negatively weighted predominately by diatoms, and positively weighted by a large summer-dominant dinoflagellate. In this analysis, the negative regression coefficients (Table 2) imply that negative PC scores contribute to higher values of $P_{\text {max }}^{B}$. Negative PC scores are generated by negative deviations from the mean of large dinoflagellates and positive deviations of the diatoms listed in Table 3. The direction of the effect in each case is therefore consistent with overall sizeand taxonomic dependencies observed for phytoplankton growth rates (Banse 1982, Tang 1995). It is possible that a more integrative index based on diagnostic photopigments would be a more robust predictor than these PC scores based on species counts (Bouman et al. 2005). In shorter-term studies, the

Table 3. Weightings of eigenvectors of dominant contributors to the fifth and fourth principal component (PC) scores, which were retained as significant predictors of $P^{B}{ }_{\max }$ for, respectively, the complete year, and data selected for the month of September

\begin{tabular}{|lr|lrl|}
\hline PC 5 taxa & Weighting & & PC 4 taxa & Weighting \\
\cline { 1 - 1 } Thalassiosira sp. & -0.280 & & Cyclotella glomerata & -0.504 \\
Leptcylindrus minimum & -0.261 & & Prorocentrum minimum & -0.362 \\
Nitschia longissima & -0.252 & & Skeletonema costatum & -0.346 \\
& & & Thalassiosira sp. & -0.343 \\
& & & T. pseudonana & -0.251 \\
Heterocapsa rotundata & 0.535 & & Gyrodinium uncatenum & 0.230 \\
Pyramimonas sp. & 0.306 & & \\
Chlamydomonas sp. & 0.274 & & \\
Chroomonas sp. & 0.247 & & & \\
& & & & \\
\end{tabular}

effect of species composition on $P^{B}{ }_{\text {max }}$ is sometimes much stronger than observed here (e.g. Côté \& Platt 1983, Gallegos 1992). Stronger relationships can be expected when there are clear demarcations between a few fast- versus slow-growing species, whether observed based on spatial distributions (Gallegos 1992) or on the time scale of a single bloom (Côté \& Platt 1983). In a longer-term study such as this, the relationship is degraded both by the limited variance in the species composition described by the PC scores (Gallegos et al. 2010), and by noise in the underlying allometric relationships between growth rate and cell size and taxonomic composition (Banse 1982, Tang 1995) noted above for the balanced growth physiological approach. Our expectations for the explanatory value of species composition data for predicting $P^{B}{ }_{\max }$ values should therefore be tempered by an understanding of the complexity of the species dynamics in the region of interest.

Too much importance should not be ascribed to the observation of a downward trend in $P^{B}$ max (Table 1). Note that an increasing trend in chl $a$ was observed over the 20 yr reported here (Table 1), while no such trend was observed in an analysis of a longer time series of chl $a$ in the Rhode River dating back to 1970 (Gallegos et al. 2010). Decadal scale oscillations were apparent in chl a (Gallegos et al. 2010), and it is possible that longer-term observations of $P^{B}{ }_{\max }$ and IC would reveal similar changes that would eliminate the appearance of a trend.

\section{Temporal stability of parameter estimates}

Most attempts to derive relationships between $P^{B}{ }_{\text {max }}$ and environmental parameters are based on studies of considerably shorter duration than this one (Pennock \& Sharp 1986, Lohrenz et al. 1994, Harding et al. 2002). It is legitimate to ask what was learned from $20 \mathrm{yr}$ of measurements that was not apparent in the first 1 to $3 \mathrm{yr}$. When regressions were performed on data from individual years, the estimate of the coefficient multiplying $\ln (T)$ varied by more than a factor of 6 (Fig. 8A). For the data transformations used, a coefficient value of 0.614 translates to a $Q_{10}$ of 2, the commonly assumed value for enzymatic processes. The coefficient estimates based on analysis of individual years imply $Q_{10}$ factors ranging from 0.36 to 4.5 , while the coefficient based on all years, 0.47 , implies a $Q_{10}$ of 
1.2. A $Q_{10}$ smaller than 2 is expected for this system because a curve for $Q_{10}=2$ provides an approximate upper bound to the data, and the overall response to temperature by the bulk of the data is considerably weaker than the upper bound (Fig. 5A). Statistical models estimated on a single year of data therefore have a high chance of not generally characterizing the response of the system in a multiple-year study, even in cases in which the coefficient of determination indicates a statistically reliable regression (cf. Fig. 8A,C, for 1991). Three and 5 yr groupings of the data reduced the variability in estimated coefficients to within 40 and $15 \%$, respectively, of the final estimates (Fig. 8A). Nevertheless, the time required for parameters in the statistical models to achieve $10 \%$ ( $7 \mathrm{yr}$ ) or $5 \%$ (13 yr) of their final values is considerably longer than the typical study.

The length of the record reported here and the eventual stability of statistical parameter estimates suggests that unbiased, if not especially precise, estimates of $P^{B}$ max may be made in the future from measurements of environmental correlates alone. While an empirical statistical approach lacks the mechanistic foundation of a physiological approach, the fit was better, as was the prediction of seasonal and interannual variations. The 2 predictors accounting for most of the variance are important components of climate change. Additionally, the first 4 predictors, i.e. $T$, IC (Wang et al. 2007), chl $a$, and $K_{d}$ (Moore et al. 1997, 2012), are amenable to long-term in situ monitoring, suggesting that high density and semi-automated estimates of $P^{B}{ }_{\max }$ may be an eventual possibility.

Acknowledgements. Thanks to S. Hedrick for measurements of ${ }^{14} \mathrm{C}$ uptake, and N. Kobayashi, A. M. Hartsig, K. Jarriel, and S. Benson for assistance in the field. Funding was provided by the Smithsonian Environmental Sciences Program and federal funds of the Smithsonian Institution.

\section{LITERATURE CITED}

Banse K (1982) Cell volumes, maximal growth rates of unicellular algae and ciliates, and the role of ciliates in the marine pelagial. Limnol Oceanogr 27:1059-1071

Behrenfeld MJ, Marañón E, Siegel DA, Hooker SB (2002) Photoacclimation and nutrient-based model of lightsaturated photosynthesis for quantifying oceanic primary production. Mar Ecol Prog Ser 228:103-117

Behrenfeld MJ, Prasil O, Babin M, Bruyant F (2004) In search of a physiological basis for covariations in lightlimited and light-saturated photosynthesis. J Phycol 40: 4-25

Bouman H, Platt T, Sathyendranath S, Stuart V (2005) Dependence of light-saturated photosynthesis on temperature and community structure. Deep-Sea Res I 52: 1284-1299
Bubenheim DL, Bugbee B, Salisbury FB (1988) Radiation in controlled environments: influence of lamp type and filter material. J Am Soc Hortic Sci 113:468-474

> Cloern JE, Grenz C, Vidergar-Lucas L (1995) An empirical model of the phytoplankton chlorophyll:carbon ratiothe conversion factor between productivity and growth rate. Limnol Oceanogr 40:1313-1321

Côté B, Platt T (1983) Day-to-day variations in the springsummer photosynthetic parameters of coastal marine phytoplankton. Limnol Oceanogr 28:320-344

Cullen JJ (1990) On models of growth and photosynthesis in phytoplankton. Deep-Sea Res 37:667-683

> Domingues RB, Anselmo TP, Barbosa AB, Sommer U, Galvão HM (2011) Light as a driver of phytoplankton growth and production in the freshwater tidal zone of a turbid estuary. Estuar Coast Shelf Sci 91:526-535

Eppley RW (1972) Temperature and phytoplankton growth in the sea. Fish Bull 70:1063-1085

Fasham MJR, Platt T (1983) Photosynthetic response of phytoplankton to light: a physiological model. Proc R Soc Lond B Biol Sci 219:355-370

Flynn KJ (2003) Do we need complex mechanistic photoacclimation models for phytoplankton? Limnol Oceanogr 48:2243-2249

Gallegos CL (1992) Photosynthesis, productivity, and species composition in a eutrophic sub-estuary: comparison of bloom and non-bloom assemblages. Mar Ecol Prog Ser 81:257-267

Gallegos CL, Jordan TE, Correll DL (1992) Event-scale response of phytoplankton to watershed inputs in a subestuary: timing, magnitude, and location of phytoplankton blooms. Limnol Oceanogr 37:813-828

Gallegos CL, Jordan TE, Correll DL (1997) Interannual variability in spring bloom timing and magnitude in the Rhode River, Maryland, USA: observations and modeling. Mar Ecol Prog Ser 154:27-40

> Gallegos CL, Jordan TE, Hines AH, Weller DE (2005) Temporal variability of optical properties in a shallow, eutrophic estuary: seasonal and interannual variability. Estuar Coast Shelf Sci 64:156-170

> Gallegos CL, Jordan TE, Hedrick SS (2010) Long-term dynamics of phytoplankton in the Rhode River, Maryland (USA). Estuaries Coasts 33:471-484

Gameiro C, Zwolinski J, Brotas V (2011) Light control on phytoplankton production in a shallow and turbid estuarine system. Hydrobiologia 669:249-263

Geider RJ (1987) Light and temperature dependence of the carbon to chlorophyll a ratio in microalgae and cyanobacteria: implications for physiology and growth of phytoplankton. New Phytol 106:1-34

- Geider RJ, MacIntyre HL, Kana TM (1998) A dynamic regulatory model of phytoplankton acclimation to light, nutrients and temperature. Limnol Oceanogr 43: 679-694

Harding LW Jr (1994) Long-term trends in the distribution of phytoplankton in Chesapeake Bay: roles of light, nutrients and streamflow. Mar Ecol Prog Ser 104:267-291

> Harding LW Jr, Prezelin BB, Sweeney BM, Cox JL (1982) Diel oscillations of the photosynthesis-irradiance (P-I) relationship in natural assemblages of phytoplankton. Mar Biol 67:167-178

Harding LW Jr, Mallonee ME, Perry ES (2002) Toward a predictive understanding of primary productivity in a temperate, partially stratified estuary. Estuar Coast Shelf Sci 55:437-463 
Harrison WG, Platt T (1980) Variations in assimilation number of coastal marine phytoplankton: effects of environmental co-variates. J Plankton Res 2:249-260

Hays GC, Richardson AJ, Robinson C (2005) Climate change and marine plankton. Trends Ecol Evol 20: 337-344

Hillebrand H, Dürselen CD, Kirschtel D, Pollingher U, Zohary $\mathrm{T}$ (1999) Biovolume calculation for pelagic and benthic microalgae. J Phycol 35:403-424

> Hines AH, Haddon AM, Wiechert LA (1990) Guild structure and foraging impact of blue crabs and epibenthic fish in a subestuary of Chesapeake Bay. Mar Ecol Prog Ser 67: 105-126

> Jassby AD, Platt T (1976) Mathematical formulation of the relationship between photosynthesis and light for phytoplankton. Limnol Oceanogr 21:540-547

Jeffrey SW, Humphrey GF (1975) New spectrophotometric equations for determining chlorophyll $a, b, c 1$, and $c 2$ in higher plants, algae and natural phytoplankton. Biochem Physiol Pflanz 167:191-194

> Jordan TE, Correll DL, Miklas J, Weller DE (1991a) Nutrients and chlorophyll at the interface of a watershed and an estuary. Limnol Oceanogr 36:251-267

> Jordan TE, Correll DL, Miklas J, Weller DE (1991b) Longterm trends in estuarine nutrients and chlorophyll, and short-term effects of variation in watershed discharge. Mar Ecol Prog Ser 75:121-132

Kimmel DG, Miller WD, Harding LW Jr, Houde ED, Roman MR (2009) Estuarine ecosystem response captured using a synoptic climatology. Estuar Coasts 32:403-409

Lewis MR, Smith JC (1983) A small volume, short-incubation-time method for measurement of photosynthesis as a function of incident irradiance. Mar Ecol Prog Ser 13: 99-102

Lewis MR, Cullen JJ, Platt T (1984) Relationships between vertical mixing and photoadaptation of phytoplankton: similarity criteria. Mar Ecol Prog Ser 15:141-149

> Lewis MR, Warnock RE, Platt T (1985) Absorption and photosynthetic action spectra for natural phytoplankton populations: implications for production in the open ocean. Limnol Oceanogr 30:794-806

Loftus ME, Place AR, Seliger HH (1979) Inorganic carbon requirements of natural populations and laboratory cultures of some Chesapeake Bay phytoplankton. Estuaries 2:236-248

> Lohrenz SE, Fahnenstiel GL, Redalje DG (1994) Spatial and temporal variations of photosynthetic parameters in relation to environmental conditions in coastal waters of the northern Gulf of Mexico. Estuaries 17:779-795

> Lorenzo LM, Figueiras FG, Tilstone GH, Arbones B, Mirón I (2004) Photosynthesis and light regime in the Azores Front region during summer: Are light-saturated computations of primary production sufficient? Deep-Sea Res I 51:1229-1244

MacIntyre HL, Kana TM, Anning T, Geider RJ (2002) Photoacclimation of photosynthesis irradiance response curves and photosynthetic pigments in microalgae and cyanobacteria. J Phycol 38:17-38

Editorial responsibility: Graham Savidge, Portaferry, UK
Malone TC, Crocker LH, Pike SE, Wendler BW (1988) Influences of river flow on the dynamics of phytoplankton production in a partially stratified estuary. Mar Ecol Prog Ser 48:235-249

> Miller WD, Harding LW Jr (2007) Climate forcing of the spring bloom in Chesapeake Bay. Mar Ecol Prog Ser 331: $11-22$

Miller WD, Kimmel DG, Harding LW Jr (2006) Predicting spring discharge of the Susquehanna River from a winter synoptic climatology for the eastern United States. Water Resour Res 42:W05414

> Moore KA, Wetzel RL, Orth RJ (1997) Seasonal pulses of turbidity and their relations to eelgrass (Zostera marina L.) survival in an estuary. J Exp Mar Biol Ecol 215:115-134

> Moore KA, Shields EC, Parrish DB, Orth RJ (2012) Eelgrass survival in two contrasting systems: role of turbidity and summer water temperatures. Mar Ecol Prog Ser 448: $247-258$

Pennock JR, Sharp JH (1986) Phytoplankton production in the Delaware Estuary: temporal and spatial variability. Mar Ecol Prog Ser 34:143-155

Peterson WT, Schwing FB (2003) A new climate regime in northeast Pacific ecosystems. Geophys Res Lett 30:1896 doi:1029/2003GLO17528

Pickett JM, Meyers J (1966) Monochromatic light saturation curves for photosynthesis in Chlorella. Plant Physiol 41: 90-98

> Platt T, Sathyendranath S (1988) Oceanic primary production: estimation by remote sensing at local and regional scales. Science 241:1613-1620

Platt T, Gallegos CL, Harrison WG (1980) Photoinhibition of photosynthesis in natural assemblages of marine phytoplankton. J Mar Res 38:687-701

Ryther JH, Yentsch CS (1957) The estimation of phytoplankton production in the ocean from chlorophyll and light data. Limnol Oceanogr 2:281-286

> Sathyendranath S, Platt T (1989) Computation of aquatic primary production: extended formalism to include effect of angular and spectral distribution of light. Limnol Oceanogr 34:188-198

- Seliger HH, Loftus ME (1974) Growth and dissipation of phytoplankton in Chesapeake Bay. II. A statistical analysis of phytoplankton standing crops in the Rhode and West Rivers and an adjacent section of the Chesapeake Bay. Chesap Sci 15:185-204

Strathmann RR (1967) Estimating the organic carbon content of phytoplankton from cell volume or plasma volume. Limnol Oceanogr 12:411-418

Strickland JDH, Parsons TR (1972) A practical handbook of seawater analysis, Vol. 167. Fisheries Research Board of Canada, Ottawa, ON

Tang EPY (1995) The allometry of algal growth rates. J Plankton Res 17:1325-1335

Wang ZA, Liu X, Byrne RH, Wanninkhof R, Bernstein RE, Kaltenbacher EA, Patten J (2007) Simultaneous spectrophotometric flow-through measurements of $\mathrm{pH}$, carbon dioxide fugacity, and total inorganic carbon in seawater. Anal Chim Acta 596:23-36

Submitted: March 23, 2012; Accepted: May 27, 2012 Proofs received from author(s): August 20, 2012 